\title{
WH-MOVEMENT IN STANDARD ARABIC: AN OPTIMALITY-THEORETIC ACCOUNT
}

\author{
Mousa A. BTOOSH \\ Al-Hussein Bin Talal University, Ma'an \\ mbtoosh@ahu.edu.jo
}

\begin{abstract}
This paper is meant to delineate the syntax of wh-movement in Standard Arabic within the Optimality Theory framework. The scope of this study is limited to examine only simple, relativized and indirect verbal information questions. Further restrictions also have been placed on tense and negation in that only past tense affirmative questions are tackled here.

Results show that Standard Arabic strictly adheres to the OP SPEC constraint in the matrix as well as the subordinate clauses. Findings also show that *Prep-Strand violation is intolerable in all types of information questions. Furthermore, the phonological manifestation of the complementizer is obligatory when the relative clause head is present or when the relative clause head is deleted and a resumptive pronoun is left behind.
\end{abstract}

KEYWORDS: Wh-movement; constraints; questions; resumptive pronouns; relative clauses.

\section{Introduction and review of literature}

Languages vary not only as to where they place wh-words or phrases, but also in the constraints governing the movement process, in general. In spite of the different kinds of movement that languages feature (topicalization, extraposition, wh-movement, heavy NP-shift, etc.), all of such syntactic phenomena do share a common property, the movement of a category from a place to another. Though its roots began long before, the unified theory of wh-movement came into being by the publication of Chomsky's article On wh-movement in 1977. Ever since, this inspiring article has opened the door for intensive research on the wh-movement process in most languages worldwide. A survey of literature shows that several syntactic theories and approaches have been employed to investigate wh-movement, including the Transformational Grammar, Principles and Parameters Theory, Minimalist Program and Optimality Theory. The diversity among these theories and approaches in how they deal with conflicts in wh-movement 
should not belie the shared fundamental goal, that is to provide conflict resolutions for such a grammatical issue.

As far as wh-movement is concerned, languages are divided into three groups: (i) whmovement languages, (ii) wh-in-situ languages and (iii) languages with optional whmovement, where the wh-phrase appears in situ or displaced. Greenberg (1966) relates wh-movement to word order. VSO languages, according to Greenberg, always have whmovement while no such process is found in SOV languages. Many of the SVO languages, on the other hand, feature wh-movement.

Wh-movement in Arabic has received a fair amount of attention over the past few decades. Many of the earlier studies investigated colloquial varieties, but few have sketched Standard Arabic (henceforth, SA). A characterization of the basic Arabic syntactic patterns, including wh-movement is provided in Bakir (1980). In her attempt to examine the behavior of wh-questions in Egyptian Arabic, Wahba (1984) details the scope of the wh-questions and islands constraints within the Government Binding framework. Farghal (1986) provides a detailed account of the wh-questions and other related matters in Arabic, including the contributions of the earlier Arab grammarians. Nouhi (1996) characterizes the various wh-constructions in Moroccan Arabic within the Government Binding framework. Shlonsky (1997) presents a contrastive study on clause structure and word order in Arabic and Hebrew. The optional wh-movement in Egyptian Arabic is thoroughly tackled in Lassadi (2005).

Since the mid-1990s, there has been increasing interest in Optimality Theory (henceforth, OT). Unlike the classical rule-based generative theory, OT defines Universal Grammar as a set of universal constraints and a basic alphabet of linguistic representational categories (Karger 1999: 4). The input and output forms are mediated by GEN and EVAL (Prince and Smolensky 1993). GEN generates an infinite number of potential candidates that can compete and could possibly be grammatical. According to Archangeli (1997), the generated candidates must be linguistic objects composed from the universal vocabulary that restricts inputs. EVAL, on the other hand, selects the optimal candidate from the set of potential candidates generated by the GEN. Regulating inputoutput mapping in OT relies on markedness as well as faithfulness constraints. Candidates are, thus, evaluated according to a set hierarchy of universal ranked constraints, called markedness constraints which limit how far candidate outputs may adhere to universal principles. In addition to markedness constraints, candidates are also evaluated according to a set hierarchy of ranked faithfulness constraints, which, in turn, "limit how far candidate outputs may differ from the input" (Legendre 2001: 4).

A close look at the relevant literature shows that research devoted to Arabic syntax within the OT framework is very scarce in comparison with studies devoted to phonology, for instance. As far as the present author can tell, no previous attempt has tackled Arabic syntax, in general, or wh-movement, particularly, within the OT framework. As such, this paper aims to fill in the gap by replacing the sequential application of the whmovement rules with the simultaneous application of OT constraints. The scope of this study is limited to cover only three types of past tense affirmative information ques- 
tions, viz., simple, relativized and indirect questions. As such, no attempt has been made to tackle verbless questions, present or future tenses, or colloquial Arabic varieties.

\section{Standard Arabic: An overview}

SA, in its simplest sense, refers to the ancient form of Arabic as codified and recorded by Arab grammarians and philologists in the first centuries of Islam. In addition to being a richly inflected variety, where mood, case, number, and gender and all grammatical functions are marked by short vowels, SA distinguishes between three numbers (singular, dual and plural) and is almost completely uniform across the Arab world (Zughoul 1980).

SA, like other Arabic varieties, is a pro-drop language. That is, a null category (pro) is allowed in the subject position of a finite clause if the agreement features on the verb are rich enough to enable content to be recovered (Baptista 1995 and Chomsky 1981). In this context, it should be made obvious that agreement features do play a great role in the order of the sentence. However, the dropping of the subject in Arabic is not arbitrary. If the sentence is SVO, then the verb achieves full agreement (in terms of number, gender and person) with the subject, allowing the subject to be dropped. However, if the sentence is VSO, then the verb fails to achieve number agreement, a feature which makes the recovery of the subject if dropped rather problematic, as shown in (1).

(1a) akal-a l-walad-u/l-Rawla:d-u t-tuffa:h at-a

ate-3.sg.masc. the boy/the boys the apple-acc.

'The boy/boys ate the apple.'

(1b) Ralwalad-u/*2al-Rawla:d-u Takala t-tuffa:h at-a the boy-nom./*the boys.nom. ate-3.sg.masc. the apple-acc.

'The boy/*boys ate the apple.'

(1c) Ral-?awla:d-u ?akal-u t-tuffa:h at-a

the boys. nom. ate-3.sg.masc. the apple-acc.

'The boys ate the apple.'

(1d) Pakal-a t-tuffa: $\hbar$ at-a

ate-3.sg.masc. the apple-acc.

'He ate the apple.'

(1e) Rakal-u t-tuffa:h at-a ate-3.pl.masc. the apple-acc.

'They ate the apple.' 
Based on the data presented above, it is evident that the pro-drop parameter becomes active only in SVO sentences, as it is the only pattern of word order in SA that allows the subject to be fully recovered. This conveys that the pro drop sentences exemplified in (1d and 1e), which preserve agreement in gender, number and person, are SVO sentences.

SA, according to traditional Basri grammarians, distinguishes between three types of sentences, viz., nominal, verbal and equational sentences. Sentences that begin with a noun are called nominal sentences, as shown in (2).

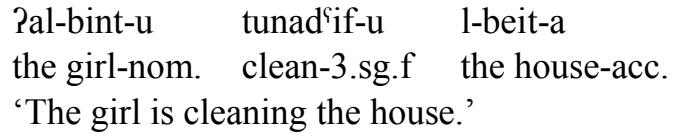

Statements that begin with a verb are referred to as verbal sentences, as exemplified in (3).

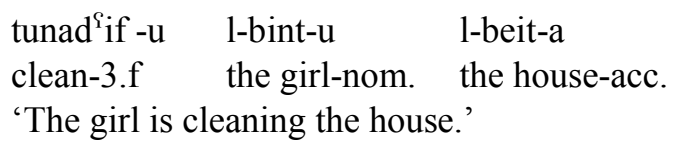

Sentences that do not contain a verb, on the other hand, are referred to as equational sentences. The lack of the copula verb yakuun 'be' in equational sentences is attributed to a general language specific parameter which disfavors the phonological manifestation of the verb yakun 'be' in the present tense.

(4) Pal-bint-u dzamilat-un the girl-nom beautiful-nom

'The girl is beautiful.'

In addition to the default nominative case (Ouhalla 1994), Arabic has genitive and accusative cases which are assigned by case governors. It should be mentioned that cases in SA mark both nouns and adjectives. Example (5) illustrates the three cases used in this variety.

(5a) kasar-a zayd-un 2af-Subba:k-a

broke-3.sg.m Zayd-nom. the window-acc.

'Zayd broke the window.'

(5b) zayd-un fi l-madrasat-i

Zayd-nom. in the school-gen.

'Zayd is in the school.' 
3. Word order and wh-Movement in Standard Arabic

Research on SA lends empirical support to the fact that this variety is typically a VSO language (Zughoul 1980; Marshad and Suleiman 1991; Fassi Fehri 1993; Belnap and Haeri 1997; Al-Shorafat 1998, to name but a few). However, this variety also allows VOS, OVS OSV and SVO owing to the importance of parsing. Two assumptions have been proposed in literature over the derivation of the VSO order, in general. The first assumption holds that the verb raises to $\mathrm{C}$ of the matrix clause. The second assumption, which is more popular in the literature of movement, holds, on the other hand, that the verb raises to AgrS/T/I. Research on Arabic has almost always favored the second assumption (Fassi Fehri 1993; Benmamoun 2000; Tamari 2001, to name but a few). Drawing on the 'VP-Internal Subject' hypothesis, both assumptions predict that SVO is the underlying configuration in SA. Building on earliest form of Minimalist Program (Chomsky 1992), Bolotin (1995) argues that VSO and SVO word order variation in SA rely on a set of inflectional parameters in which only Agr changes:

$\begin{array}{llll}\text { V features of } & \text { T } & \begin{array}{c}\text { VSO order } \\ \text { strong }\end{array} & \begin{array}{c}\text { SVO order } \\ \text { strong }\end{array} \\ \text { V features of } & \text { Agr } & \text { weak } & \text { strong } \\ \text { N features of } & \text { T } & \text { weak } & \text { weak } \\ \text { N features of } & \text { Agr } & \text { weak } & \text { strong }\end{array}$

(Bolotin 1995: 20)

According to these parameters, $\mathrm{SA}$ verbs always raise to $\mathrm{T}$ since the verbal features in VSO and SVO word orders are strong. However, verbs of only SVO sentences raise to Agr to get their strong verbal features checked off. The subject, which remains in-situ in VSO order, raises to Spec AgrP only in SVO order.

In line with the recent version of the Minimalist Program, Chomsky (2000) argues that the Agr node has no role in feature checking, since it has neither case nor theta features. As such, Agr and Tense are both located in T. Mahfoudhi (2002: 19) argues that "the difference between the SVO and VSO word orders is due to the difference in the choice of the element that moves to satisfy the EPP feature". Following Alexiadous and Anagnosopoulou (1998), Mahfoudhi argues that the verb in pro-drop languages can check the EPP feature because it has very rich morphology, which, in turn allows it to stand without the subject in a sentence.

While the verb always raises to T in both VSO and SVO orders (Benmamoun 2000; Mohammad 2000; Fakih 2006, among others), the subject remains in-situ in VSO and raises to SPEC TP in SVO (Chomsky 1995). Figures 1 and 2 present illustrative examples of both derivations, also presented as (6) and (7), respectively.

$$
\begin{array}{lll}
\text { qara2-a } & \text { zayd-un } & \text { 2al-kita:b-a } \\
\text { read-3.sg.masc. } & \text { Zayd-nom. } & \text { the book-acc } \\
\text { 'Zayd read the book.' } &
\end{array}
$$




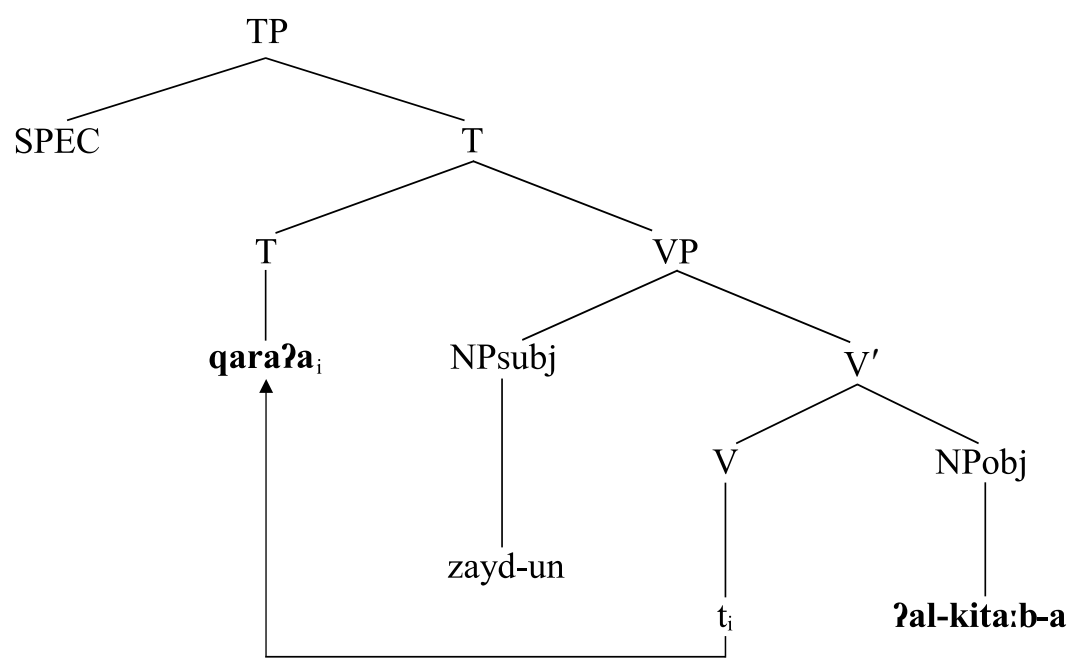

Figure 1. V-to-T movement.

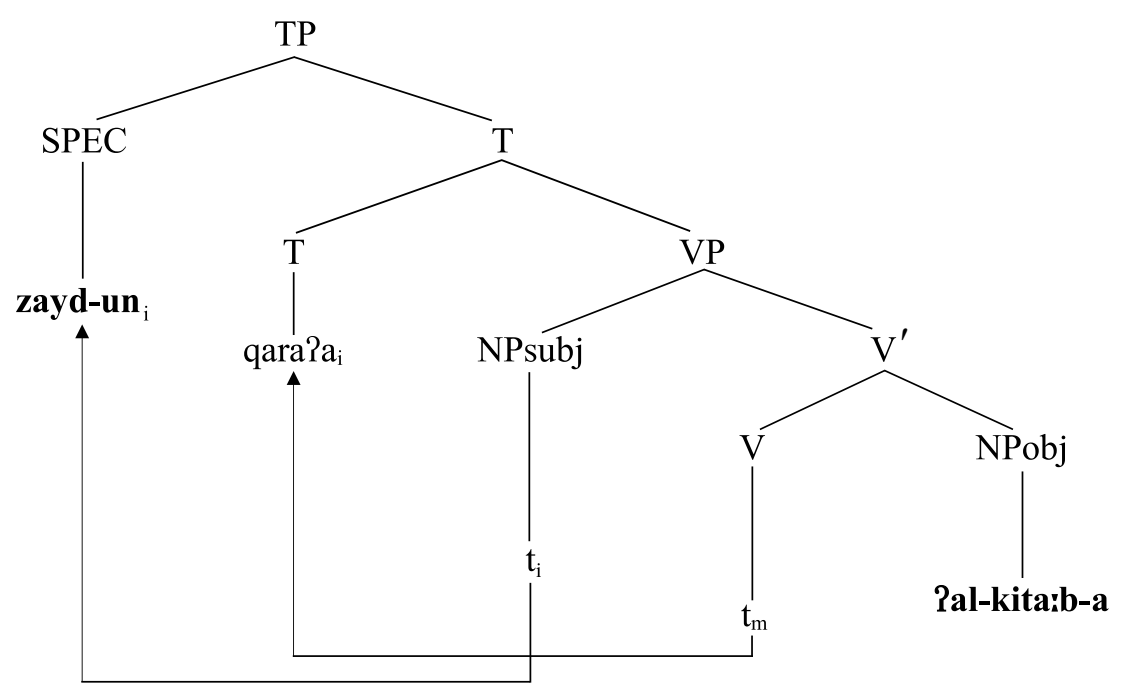

Figure 2. $\mathrm{NP}_{\text {subj }}$ movement in SVO sentences.

(7) zayd-un qarai-a 1-kita:b-a

Zayd-nom. read-3.sg.masc. the book-acc

'Zayd read the book.' 
By comparing the VSO sentences in (8a) with their SVO counterparts in (8b), it becomes obvious that both of them have full agreement in terms of gender and person. However, subject-verb agreement in number is only preserved in SVO sentences.

(8a)

(i)

kasar-a

1-Pawla:d-u

1-ba:b-a

broke-3.sg.masc. the boys-nom. the door-acc.

(agreement in gender and person)

'The boys broke the door.'

(ii) Ral Pawala:d-u kasar-u

1-ba:ba

(agreement in gender, number and person)

The boys-nom. broke-3.pl.masc. the door-acc.

'The boys broke the door.'

(8b)

(i)

kasar-at 1-bana:t-u 1-ba:ba

broke-3.sg.f the girls-nom. the door-acc.

(agreement in gender and person)

'The girls broke the door.'

(ii)

Pal bana:t-u kasarn-a

1-ba:ba

(agreement in gender, number and person)

the girls-nom broke-3.pl.f

the door- acc.

'The girls broke the door.'

SA, like most other languages, possesses wh-movement. Though wh-movement is governed by one rule (Move $\alpha$ ), it is still necessary to state clearly that this process is not constraint-free. Rather, several constraints related to the sorts of the constituents that can be moved, the landing sites that constituents can move to, and subjacency conditions, do apply. Irrespective of the question type, wh-movement in SA is triggered neither by case nor by theta role. Rather, it is solely motivated by focalization.

As far as interrogative sentences are concerned, the examples presented below allow us to maintain that both yes/no and information questions are made in SA by placing the interrogative word or particle at the beginning of a sentence without any kind of inversion. Yes/no questions show no movement at all and, thus, the difference between the question and the statement is attributed to the presence of the interrogative particles ( hal or ?a), which have the same meaning of ('does', 'do', 'did' or 'be').

$$
\begin{aligned}
& \text { na:mat } \quad \text { Pal-bint-u } \\
& \text { slept-3.sg.f The girl-nom. } \\
& \text { 'The girl slept.' }
\end{aligned}
$$

(Statement) 


\begin{tabular}{|c|c|c|c|}
\hline$(9 b)$ & $\begin{array}{l}\text { hal na:mat } \\
\mathrm{Q} \text { slept-3.sg.f } \\
\text { 'Did the girl sleep?' }\end{array}$ & $\begin{array}{l}\text { Pal-bint-u } \\
\text { the girl-nom. }\end{array}$ & (Yes/no question) \\
\hline$(9 c)$ & $\begin{array}{l}\text { Pa na:mat } \\
\text { Q } \quad \text { slept-3.sg.f } \\
\text { 'Did the girl sleep?' }\end{array}$ & $\begin{array}{l}\text { Pal-bint-u } \\
\text { the girl-nom. }\end{array}$ & (Yes/no question) \\
\hline (9d) & $\begin{array}{lll}\text { Pa } & \text { iða: } & \text { nadru } \\
Q & \text { if } & \text { we st }\end{array}$ & udy-present & $\begin{array}{l}\text { nanjah-u (Yes/no question) } \\
\text { we pass-future }\end{array}$ \\
\hline
\end{tabular}

The interrogative particles ( $h a l$ and Pa), which do not influence word order in declarative sentences, do not involve any kind of movement to CP. Rather, they are basegenerated in SPEC CP position (Shooshtari 2009). Evidence in support of this argument comes from (9d), where the particle is followed by a complementizer. This indicates that the interrogative particle originates in SPEC CP, rather than C.

As for information questions, the wh-element must move from the place where it originates (subject, object or non-argument position) to a legitimate specifier. The question pushed to the fore is: which specifiers can a wh-phrase move to? The data below show that SPEC TP and SPEC CP are considered potential legitimate positions for this purpose. Generally speaking, wh-elements (wh-subjects, wh-objects and non-argument wh-words) move to SPEC TP. However, if a complementizer is present in C, then the wh-element must move to SPEC CP. Several pieces of evidence support this argument. Carnie (2006: 318) states that the wh-phrase in Irish, which allows both wh-phrase and an overt complementizer, moves to SPEC CP, the only position available to it. Lassadi (2005: 194) argues that in Egyptian Arabic a subject wh-phrase without illi ('that/ which') occupies SPEC IP. However, this phrase must move to SPEC FP if the relative particle illi is present. Gutirrez-Bravo (2002) argues that wh-phrases in Spanish have SPEC TP as their final landing site. However, a new CP node is projected when the relative operator appears in C. These arguments provide a concrete support for Grimshaw's (1997: 37) argument "every projection is optional and is present only if it is needed". No doubt, these ideas go in harmony with Chomsky's (1995) notion of economy. Figure 3 presents example (10) where the wh-subject moves to SPEC TP.

$$
\begin{aligned}
& \text { man qara?-a 1-kita:b-a } \\
& \text { who read-3.past. sg.masc. the book-acc. } \\
& \text { 'Who read the book?' }
\end{aligned}
$$

In contrast, Figure 4 illustrates example (11) where the wh-element moves to SPEC CP.

$$
\begin{array}{ll}
\text { man allaði } \quad \text { qara?-a } & \text { 1-kita:b-a } \\
\text { who that/who read-3.past. sg.masc. } & \text { the book-acc. } \\
\text { 'Who read the book?' } &
\end{array}
$$




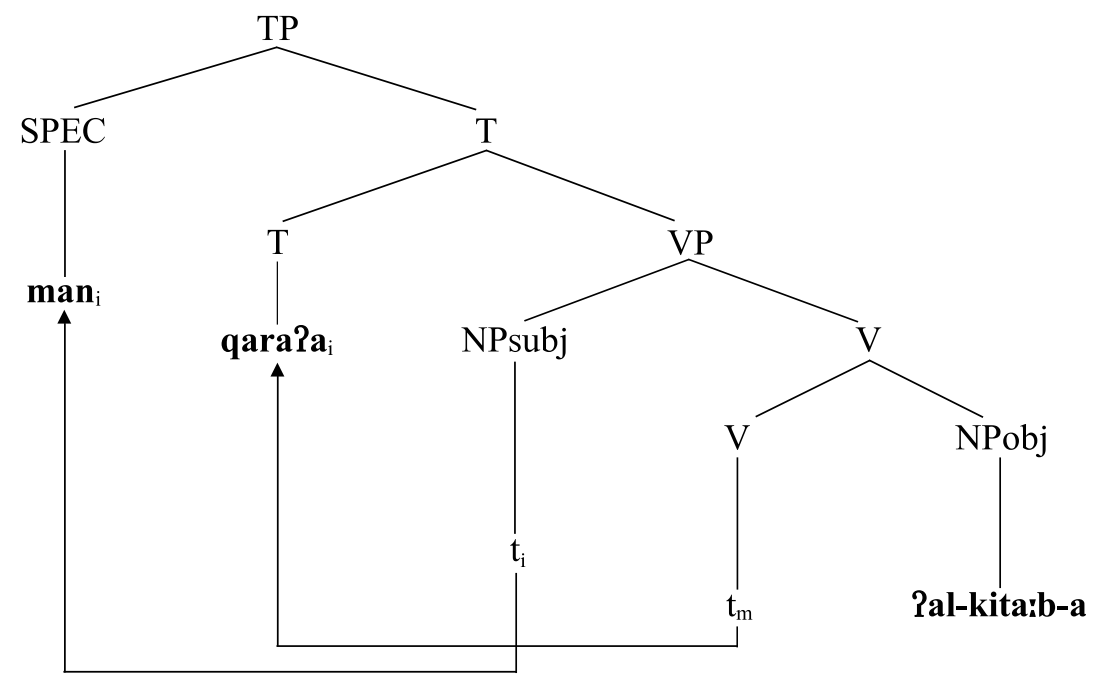

Figure 3. Wh-subject movement.

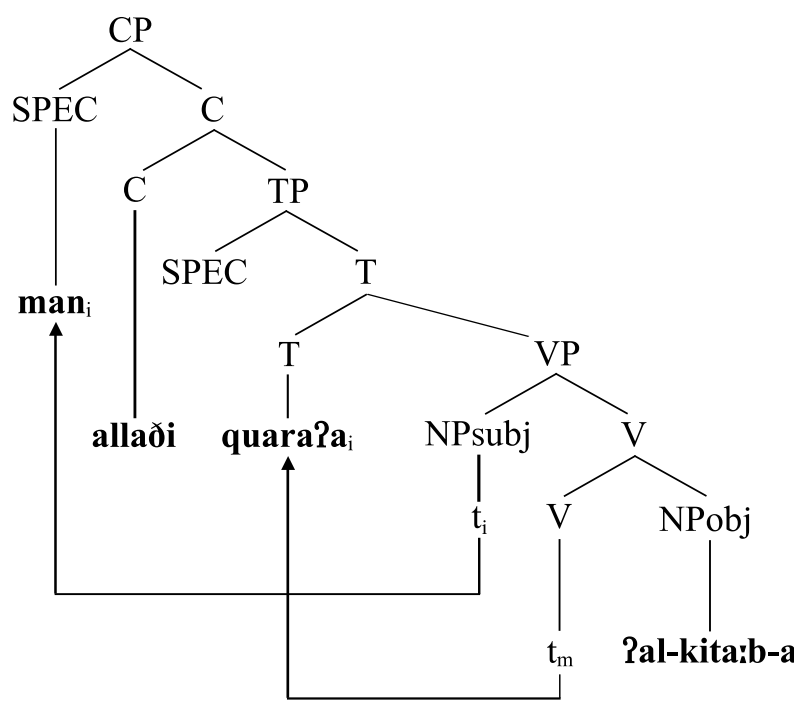

Figure 4. Wh-subject movement in relativized questions.

Wh-words in SA constitute a well-defined family that consists of nine elements: man 'who/whom', lima:ða 'why', Payn-a 'where', mata 'when', Payy 'which; who', kam 'how much/how many', kayf-a 'how', ma: 'what' and ma:ða 'what'. Like English, the wh-word in SA can be a head (of the phrase), a specifier (of the phrase) or an object of a preposition, as shown in Figure 5. 
$\left.\right|_{\text {wh-word }} ^{\mathrm{X}}$
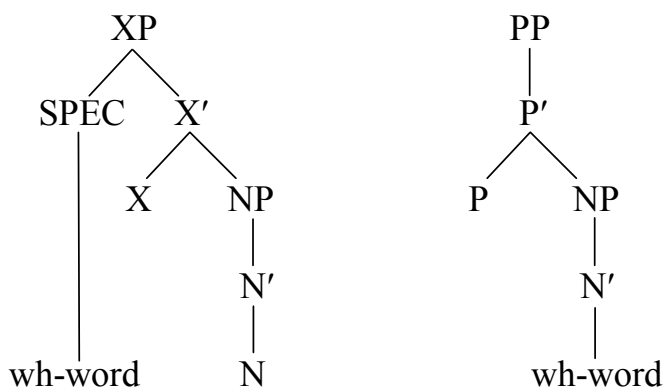

Figure 5. Potential sites of wh-words.

A close look at the following examples demonstrates that wh-elements are not alike in terms of their position in phrases.

(12a) man qail-a ha:ða

(Head)

who said-3.sg.masc. this

'Who said this?'

(12b) kam Sa:mil-an tahtaij-u

(Specifier)

how many worker-sg.masc you- 2 sg. masc. need

'How many workers do you need?'

(12c) ayya rajul-in tureed-u

(Specifier)

which man-acc. you-2 sg. masc. want-2p.sg.masc.

'Which man do you want?'

(12d) Sala man PiStad-a xalid-un (Prepositional object)

on whom attacked-3.sg.masc Xalid-nom.

'Who did Xalid attack?'

A summary of the position that each of the wh-words can occupy in a phrase is given in (13).

(13)

$\begin{array}{ccc}\text { Phrase Head } & \text { Phrase Specifier } & \text { Prepositional Object } \\ \text { man } & \text { Payy } & \text { man } \\ \text { ma:ða } & \text { kam } & \text { ma:ða } \\ \text { mata } & \text { ma: } & \text { ma: } \\ \text { kayf-a } & \text { man } & \text { Payn-a } \\ & & \text { mata }\end{array}$


To make the discussion rather more concrete and for better understanding of constraint interactions in wh-movement in SA, the bulk of this paper is divided into three subsections illustrating the formation of simple, relativized, and indirect questions.

\subsection{Simple wh-questions}

The word "simple" is used here to distinguish this type of information questions from relativized and indirect questions. In this type, the wh-word moves from its original site (wh-subject, wh-object or non-argument positions) to one of the potential specifier positions mentioned earlier (SPEC TP or SPEC CP), leaving a trace in its extraction site. The examples below show that wh-words in SA can originate in argument and nonargument positions. As far as the argument positions are concerned, wh-phrases can originate in SPEC VP or in the complement of the VP.

\subsubsection{Argument positions}

Unlike certain colloquial Arabic varieties (e.g. Egyptian Arabic, Jordanian Arabic, etc.), which alternate between moving the wh-phrase or leaving it in-situ, leaving the whword in situ is banned in SA. As such, the wh-word in SA questions must end up in a legitimate specifier position in the matrix and subordinate clauses. Building on these notions and in order for the wh-movement to take place, OP SPEC must dominate STAY.

(14) OPERATOR in SPECIFIER (OP SPEC)

Syntactic operators must be in specifier position.

(Grimshaw 1997)

(15) Economy of Movement (STAY)

Trace is not allowed.

(Grimshaw 1997)

The rank of OP SPEC over STAY in Tableau 1 illustrates that the movement of the whword to SPEC CP in SA is a must so as to win the competition. As such, the violation of OP SPEC, as shown below, is intolerable and results in excluding the first candidate from the race.

$$
\begin{aligned}
& \text { Input: ra?-a zayd-un man } \\
& \text { saw-3.sg.masc. Zayd-nom. who } \\
& \text { 'Who did Zayd see?' }
\end{aligned}
$$


OP SPEC $>>$ STAY

\begin{tabular}{|l|c|c|}
\hline ra?a $(\mathrm{x}, \mathrm{y}), \mathrm{X}=$ zayd-un, $\mathrm{Y}=(\mathrm{man})$ & OP SPEC & STAY \\
\hline a. $[\mathrm{vp}$ zayd-un ra?-a man] & $* !$ & \\
\hline b. $\left[\mathrm{TP} \operatorname{man}_{\mathrm{i}}\left[\mathrm{T}\right.\right.$ ra?-a $\left.\mathrm{a}_{\mathrm{k}}\right]\left[\mathrm{vp}\right.$ zayd-un $\left.\left.\mathrm{t}_{\mathrm{k}} \mathrm{ti}\right]\right]$ & & $* *$ \\
\hline
\end{tabular}

Tableau 1.

The first candidate is ruled out, as it violates the top-ranked constraint OP SPEC, which outranks all other constraints in this variety. Even though it is not perfect, due to its double violations of low-ranked constraint, candidate (b) comes out as optimal by escaping the penalty of the intolerable OP SPEC constraint. According to OT tenets, it is important for the winner to escape the penalty of the top-ranked constraint irrespective of the number of the incurred violations of the low-ranked constraints (Prince and Smolensky 1993; Karger 1999, among others).

The interaction between OP SPEC and STAY in a variety that does not allow for wh-in-situ establishes for a permanent fact that these two constraints are always in conflicting positions. In addition to the strict adherence to OP SPEC, potential optimals in wh-questions which originate in argument positions must adhere to OB HD. As such, OB HD dominates STAY.

Obligatory Head (OB-HD)

A projection has a head.

(Grimshaw 1997)

A close look at Tableau 2 shows that in spite of its strict adherence to OP SPEC, the second candidate (b) fails to win the race. Therefore, another constraint (OB HD) is posited here to distinguish between legitimate and illegitimate landing sites of the whelement.

$$
\begin{aligned}
& \text { Input: qara?-a man ?al-kita:b-a } \\
& \text { read-3.past. sg.masc. who the book-acc. }
\end{aligned}
$$

'Who read the book?'

Constraint ranking in Tableau (2) works out to rule out all candidates except for candidate (c). Candidate (a) fails to win the competition by the block imposed by SPEC OP which bans leaving the wh in-situ. Candidate (b), which places more value on movement of the wh-element to a specifier position, is eliminated by OB HD since the highest projection $(\mathrm{CP})$ is left headless. The third candidate, on other hand, satisfies all the high ranked constraints, and thus, wins the competition. 


\begin{tabular}{|c|c|c|c|}
\hline qara?-a $(x, y), X=$ man, $Y=$ ?al-kita:b-a & OP SPEC & OB HD & STAY \\
\hline a. [тр [т qara?-a $\left.\mathrm{a}_{\mathrm{i}}\right]$ [vр man $\mathrm{t}_{\mathrm{i}}$ ?al-kita:b-a]] & $* !$ & & $*$ \\
\hline b. [CP $\operatorname{man}_{\mathrm{i}}$ e [TP $\mathrm{t}_{\mathrm{i}}$ [VP qara1-a l-kita:b-a]]] & & $* !$ & $* *$ \\
\hline c. $\left[{ }_{\mathrm{TP}} \operatorname{man}_{\mathrm{i}}\left[\mathrm{T}\right.\right.$ qara?-a $\left.{ }_{\mathrm{k}}\right]\left[\mathrm{vP}_{\mathrm{i}} \mathrm{t}_{\mathrm{k}}\right.$ l-kita:b-a $]$ & & & $* *$ \\
\hline
\end{tabular}

Tableau 2.

\subsubsection{Non-argument positions}

In light of the analyses presented so far, it is worth noting that the wh-element that originates in a non-argument position behaves just like those that originate in argument positions in terms of the strict adherence to SPEC OP, but not to OB HD. The movement of the non-argument wh-element to SPEC TP renders the question ungrammatical as it violates the Structure Preservation constraint, which blocks the movement of the non-argument element to an argument position. s such and in order to avoid incurring a violation of this constraint, the non-argument wh-element moves to SPEC CP.

(19) Structure Preservation

No movement can alter the basic X-bar nature of structure (Emonds 1976)

Drawing on the OT tenets, a constraint that is more highly ranked has a priority over another one that is lower in hierarchy. Tableau 3 shows that Structure Preservation constraint is given priority over $\mathrm{OB} \mathrm{HD}$, which is undominated when it comes to whelements that originate in argument positions. This finding gives evidence in support of Prince and Smolensky's (1993) argument concerning the violability of constraints.

$$
\begin{aligned}
& \text { Input: ðahab-a xalid-un mata } \\
& \text { went-3.sg.masc. xalid-nom. when }
\end{aligned}
$$

\begin{tabular}{|c|c|c|c|c|}
\hline $\begin{array}{l}\text { ðahab-a (x), X= xalid-un, } \\
\text { (Non-Argument/Adverb } Y=\text { mata) }\end{array}$ & $\begin{array}{c}\text { OP } \\
\text { SPEC }\end{array}$ & $\begin{array}{l}\text { Str. } \\
\text { Pres }\end{array}$ & OB HD & STAY \\
\hline a. [TP [T ðahab-a $\left.\mathrm{a}_{\mathrm{i}}\right]$ [vP xalid-un $\mathrm{t}_{\mathrm{i}}$ mata]] & $* !$ & & & * \\
\hline b. $\left[\right.$ TP mata $_{\mathrm{i}}\left[\mathrm{T}\right.$ ðahab-a $\left.{ }_{\mathrm{k}}\right]\left[\mathrm{vP}\right.$ xalid-un $\left.\left.\mathrm{t}_{\mathrm{k}} \mathrm{t}_{\mathrm{i}}\right]\right]$ & & $* !$ & & $* *$ \\
\hline c. $\left[{ }_{\mathrm{CP}}\right.$ mata $_{\mathrm{i}}\left[{ }_{\mathrm{T}}\right.$ ðahab-a $\left.{ }_{\mathrm{k}}\right]\left[\mathrm{vP}\right.$ xalid-un $\left.\left.\mathrm{t}_{\mathrm{k}} \mathrm{t}_{\mathrm{i}}\right]\right]$ & & & * & ** \\
\hline
\end{tabular}

OP SPEC, Str. Pres $>>$ OB HD, STAY

Tableau 3. 
The first candidate, which strictly adheres to OB HD, breaches the fatal OP SPEC. Candidate (b) fails to survive by violating the Str. Pres constraint, which blocks the movement of the wh-word from a non-argument position to an argument slot. Despite having violated STAY twice, candidate (c) survives and wins the race simply by satisfying the two top-ranked constraints.

\subsubsection{Prepositional stranding and pied piping}

In addition to being a phrase head or specifier, the wh-word might be an object of a preposition. The immediate question that such a possibility gives rise to: does SA allow prepositional stranding and/or pied piping? As prepositions in SA are followed or linked by a noun or pronoun, then, prepositional stranding, in its literal sense, is not allowed in this variety. Put it differently, the phonological manifestation of the resumptive pronoun that must be left behind prevents pure prepositional stranding from taking place in SA. So, the violation of the prepositional stranding constraint is intolerable.

\section{(21) *Prep-Strand}

The object of a preposition must form a conjoined structure constituent with the preposition. (Broadwell 2002)

However, the situation is entirely altered when it comes to the ban imposed on pied piping, since the preposition, together with its (wh-) complement must move to a legitimate specifier in all kinds of information questions. As such, the satisfaction of *Prep-Strand in SA is given priority over PIED PIPING.

\section{PIED PIPING}

Do not pied-pipe.

(Gouskova 2001)

The constraint interactions in Tableau 4 reflect a situation where the preposition and its object form one constituent. As such, the violation of Prep-Strand renders the question ungrammatical.
(23) Input:
PiStad-a
xalid-un Sala man
attacked-3.sg.masc. Xalid-nom. on whom
'Who did Xalid attack?'

By prioritizing the satisfaction of the *Prep-Strand over PIED PIPPING and STAY, candidate (a), which adjoins the preposition and its object, wins the competition in spite of incurring three violations of the two rightmost constraints. Since prepositional stranding is not allowed, then the violation of PIED PIPPING becomes a must in order to avoid the violation of OP SPEC. The adherence of (b) to the three constraints (*PrepStrand, OB HD and PIED PIPPING) definitely does not suffice to rescue this candidate 
OP SPEC, *Prep-Strand, OB HD >> PIED PIPPING, STAY

\begin{tabular}{|c|c|c|c|c|c|}
\hline PiStad-a $(\mathrm{x}, \mathrm{y}), \mathrm{X}=$ xalid-un, $\mathrm{Y}=$ Sala man & $\begin{array}{l}\text { OP } \\
\text { SPEC }\end{array}$ & *Prep- & OB HD & $\begin{array}{c}\text { PIED } \\
\text { PIPPING }\end{array}$ & STAY \\
\hline a. $\left[\mathrm{TP}_{\mathrm{TP}}\right.$ Sala $\operatorname{man}_{\mathrm{k}}\left[\mathrm{T}\right.$ PiStad-a $\left.\mathrm{a}_{\mathrm{i}}\right]$ [vP xalid-un $\left.\left.\mathrm{t}_{\mathrm{k}} \mathrm{t}_{\mathrm{i}}\right]\right]$ & & & & * & $* *$ \\
\hline b. [vp xalid-un ${ }_{i}$ PiStad-a $t_{i}$ ala man] & $* !$ & & 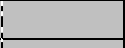 & & $*$ \\
\hline $\begin{array}{l}\text { c. [CP } \text { Sala }_{\mathrm{i}} \text { e [TP } \mathrm{t}_{\mathrm{i}} \text { PiStad-a } \mathrm{a}_{\mathrm{k}} \text { [vP Xalid-un } \mathrm{t}_{\mathrm{k}} \mathrm{t}_{\mathrm{i}} \\
\text { man]]] }\end{array}$ & *! & *! & *! & & $* * *$ \\
\hline
\end{tabular}

Tableau 4

from elimination, as it fatally violates the OP SPEC. The last candidate, on the other hand, incurs three fatal violations in addition to three violations of STAY. It violates *Prep-Strand by separating the preposition from its sister. It also violates OB HD by leaving the $\mathrm{CP}$ headless. Moreover, this candidate incurs a harsh violation of OP SPEC by leaving the wh-word in-situ.

\subsection{Relativized questions}

In spite of the shared (postnominial) position of the relative clause in both SA and English, they still show divergence in terms of the use of the relative pronoun based on the indefiniteness of the antecedent noun (Hamdallah and Tushyeh 1998). In English, the relative pronoun follows either definite or indefinite antecedent. However, the situation is different in SA in that the relative pronoun follows only a definite antecedent, as shown in (24).

\begin{tabular}{|c|c|c|c|c|}
\hline 4a) & $\begin{array}{l}\text { man } \text { Par-rajul-u } \\
\text { which/who the man-nom. } \\
\text { 'Which man did Zayd hit?' }\end{array}$ & $\begin{array}{l}\text { llad } \\
\text { that }\end{array}$ & $\begin{array}{l}\text { d'araba-(hu) } \\
\text { hit-3 sg. masc (him) }\end{array}$ & $\begin{array}{l}\text { zayd-un } \\
\text { Zayd-nom. }\end{array}$ \\
\hline & $\begin{array}{l}\text { *man rajul-u 1 la } \\
\text { which/who man-nom. th. } \\
\text { 'Which man did Zayd hit?' }\end{array}$ & & $\begin{array}{ll}\text { d'araba-(hu) } & \text { zay } \\
\text { hit-3.sg.masc (him) } & \text { Zay }\end{array}$ & -un \\
\hline
\end{tabular}

The eight forms of the relative pronoun in SA illustrated in (25) show that the relative pronoun agrees with the antecedent in gender, number and case.

a. allaði 'who, that, which'

$$
\left[\begin{array}{l}
+ \text { masculine } \\
+ \text { singular } \\
\pm \text { nominative }
\end{array}\right]
$$

b. allati 'who, that, which'

$$
\left[\begin{array}{l}
\text {-masculine } \\
+ \text { singular } \\
\pm \text { nominative }
\end{array}\right]
$$


c. allaðaani 'who, that, which'

$$
\left[\begin{array}{l}
+ \text { masculine } \\
+ \text { dual } \\
+ \text { nominative }
\end{array}\right]
$$

e. allaðavni 'who, that, which'

$$
\left[\begin{array}{l}
+ \text { masculine } \\
+ \text { dual } \\
\text {-nominative }
\end{array}\right]
$$

g. allaðiina 'who, that, which'

$$
\left[\begin{array}{l}
+ \text { masculine } \\
+ \text { plural } \\
+ \text { nominative }
\end{array}\right]
$$

d. allataani 'who, that, which'

$$
\left[\begin{array}{l}
\text {-masculine } \\
+ \text { dual } \\
+ \text { nominative }
\end{array}\right]
$$

f. allatayni 'who, that, which'

$$
\left[\begin{array}{l}
- \text { masculine } \\
+ \text { dual } \\
- \text { nominative }
\end{array}\right]
$$

h. allati 'who, that, which'

$$
\left[\begin{array}{l}
\text {-masculine } \\
+ \text { plural } \\
\text { +nominative }
\end{array}\right]
$$

The phonological manifestation of the relative pronoun in SA questions is obligatory when the head of the relative clause is present or when the head of the relative clause is deleted and a resumptive pronoun is left behind, irrespective of the presence or absence of the copula. This conveys that the overt realization of the complementizer is optional elsewhere. Illustrative examples are given in (26).
(26a) man Pal-fata:t-u llati na:mat mubakkir-an (Obligatory) which the girl-nom. that slept-3.sg. masc. early
'Which girl slept early?'
(26b) man $\begin{array}{lll}\text { allaði } & \text { d'araba-hu } & \text { zayd-un } \\ \text { that } & \text { hit-3.sg. masc (him) } & \text { Zayd-nom. }\end{array}$ 'Who did Zayd hit?'
man
(allaði) d'arab-a
yd-un
who (that)
hit-3.sg.masc. Zayd-nom.
'Who did Zayd hit?'
(Obligatory)

The data presented above show that the phonological manifestation of the relative pronoun is obligatory in both (26a) and (26 b) while it is optional in (26c). The assumption about the obligatory phonological manifestation of the relative particle requires us to distinguish between grammatical and ungrammatical questions, as illustrated in (24).

The deletion of the relative pronoun when the relative clause head is present or when the head is deleted and a resumptive pronoun is left behind is disfavored by FAITH [COMP]. 
The output value of $[ \pm \mathrm{COMP}]$ is the same as the input value. (Müller 1999)

At all accounts, the overt realization of the relative pronoun in $\mathrm{C}$ is disfavored by Wh$\mathrm{C}$, which bans the pronunciation of the complementizer in $\mathrm{C}$ when the phrase is pronounced in SPEC CP.

\section{(28) Wh-C Constraint}

No complementizer is pronounced in $\mathrm{C}$ when a phrase is pronounced in SPEC $(\mathrm{CP})$.

(Pesetsky 1997)

The question immediately pushed to the fore here: are resumptive pronouns allowed in SA? A careful examination of the examples in (29) reveals three major findings. First, resumptive pronouns (in both relativized and non-relativized questions) are prohibited in the highest subject position of the matrix clause, optional in the object position and mandatory as objects of prepositions. Thus, SA strictly adheres to Highest Subject Restriction, which prohibits resumptive pronouns in the highest subject position of the relative clause. Similar findings have been reported in previous research of a variety of languages (McCloskey 1990; Shlonsky 1992; Shlonsky 2002, among others). Second, resumptive pronoun strategy in SA is the property of relatives rather than whmovement. Evidence in support of this argument is found in Farghal (1986). Third, resumptive pronouns come into play only when the gap derivational fails (Shlonsky 1992).
(29a) *man ?al-fata:t-u llati heya ?akalat ?at-tuffa:hat-a (Prohibited) which/who the girl that ate-3.sg.f the apple-acc.
'Which girl ate the apple?'

man Par-rajul-u llaði $d^{\text {`araba- }(\boldsymbol{h} \boldsymbol{u})}$ zayd-un
which/who the man that
'Whit-3.sg.masc. Zayd. nom.
man
allaði d'araba- $(\boldsymbol{h} \boldsymbol{u})$
zayd-un
(Optional)
which/who that hit-3.sg.masc. (him) Zayd-nom.
'Who did Zayd hit?'
(29d) *man d araba *hu Zaydun
(Prohibited)
who hit-3. sg.masc. Zayd-nom.
'Who did Zayd hit?'
(29e) ayu fata:t-in ?axð-ta min-ha- ?annugood-a (Obligatory) which girl-acc. you-2.sg.masc. took from her the money-acc.
'Which girl did you take the money from?'


Before proceeding, two points should be highlighted. First, the preservation of the resumptive pronoun in the absence of the relative pronoun renders the question ungrammatical, as shown in (29d). Second, as the examples in (29) illustrate there is no difference between d-linked and non d-linked interrogatives in terms of the presence and absence of resumptive pronouns.

At all accounts, leaving a resumptive pronoun in relativized questions will always result in a violation of $*$ RES.

No Resumptive Pronoun (*RES)

Don't have a resumptive pronoun.

(Keer 1999)

As can be seen in Tableau 5, the decision regarding which candidate is optimal is made by the three top constraints OP SPEC, FAITH [COMP] and OB HD. The low rank of *RES here reflects that the optional manifestation of the resumptive pronoun is in the object position.

$$
\begin{aligned}
& \text { Input: Par-rajul-a llaði d } \mathrm{d}^{\mathrm{S}} \mathrm{arab}-\mathrm{a}(\mathrm{hu}) \quad \text { zayd-un man } \\
& \text { the man-acc. that hit-3.sg.masc. (him) Zayd-nom. who }
\end{aligned}
$$

\begin{tabular}{|c|c|c|c|c|c|c|}
\hline $\begin{array}{l}\text { d'arab-a }(x, y), X=Z a y d-u n, \\
Y=\text { man Par-rajul-u }\end{array}$ & $\begin{array}{c}\text { OP } \\
\text { SPEC }\end{array}$ & $\begin{array}{l}\text { FAITH } \\
{[\mathrm{COMP}]}\end{array}$ & OB HD & $*$ RES & Wh-C & STAY \\
\hline $\begin{array}{l}\text { a. [CP man Par-rajul- } \mathrm{u}_{\mathrm{i}} \\
\left.\left[\mathrm{TTP}_{\mathrm{i}}\left[\mathrm{t}_{\mathrm{VP}} \text { d'arab-a } \mathrm{a}_{\mathrm{k}} \text { zayd-un } \mathrm{t}_{\mathrm{k}} \mathrm{t}_{\mathrm{i}}\right]\right]\right]\end{array}$ & & $* !$ & *! & & & $* * *$ \\
\hline 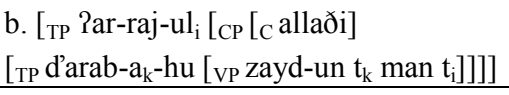 & *! & & & * & & $* *$ \\
\hline $\begin{array}{l}\text { c. }[\mathrm{CP} \text { man Par-raj-ul } \text { [c allaði }] \\
\left.\left[\mathrm{TTP}_{\mathrm{i}}\left[\mathrm{T} \text { d'araba }{ }_{\mathrm{k}}-\mathrm{hu}\right]\left[\mathrm{vP} \text { zayd-un } \mathrm{t}_{\mathrm{k}} \mathrm{t}_{\mathrm{i}}\right]\right]\right]\end{array}$ & & $!$ & & $*$ & * & $* *$ \\
\hline
\end{tabular}

$$
\text { OP SPEC, FAITH [COMP], OB HD }>\text { *RES, Wh-C, STAY }
$$

Tableau 5 .

The first candidate is excluded by the faithfulness constraint FAITH [COMP], which penalizes the deletion of the complementizer. Furthermore, the same candidate is also ruled out by OB HD since the highest projection is left headless. As the input complementizer has a corresponding output, candidate (b) perfectly satisfies FAITH [COMP]. However, this candidate is ruled out due to incurring a violation of OP SPEC. Candidate (c) violates the three rightmost constraints more severely than any of its competitors. However, it wins the race by satisfying the three top-ranked constraints. 
The evaluation of the candidates in Tableau 6 sheds further light on the notion of constraint ranking. It explains how *RES operates with trace in the highest subject position of the matrix clause. While low-ranked at object position, *RES is undominated in the highest subject position. To have a constraint that is violable in one context and inviolable in the other is, of course, one of the most basic properties of OT doctrine, as shown above.

$$
\begin{aligned}
& \text { Input: Pal-fata:t-u llati } *(\text { heya }) \text { Pakalat } \\
& \begin{array}{l}
\text { Pat-tuffa:hat-a man } \\
\text { the girl that ate-3.sg.f }
\end{array} \\
& \text { 'Whe apple-acc. who } \\
& \text { 'Which girl ate the apple?' }
\end{aligned}
$$

\begin{tabular}{|c|c|c|c|c|c|c|}
\hline $\begin{array}{l}\text { Pakalat }(x, y), X=\text { man Pal-fata:t-u, } \\
Y=\text { ?at- tuffa: } \hbar \text { at-a }\end{array}$ & $\begin{array}{c}\text { OP } \\
\text { SPEC }\end{array}$ & $\begin{array}{l}\text { FAITH } \\
{[\mathrm{COMP}]}\end{array}$ & OB HD & ${ }^{*} \mathrm{RES}$ & Wh-C & STAY \\
\hline $\begin{array}{l}\text { a. [CP man Pal-fata:t-u } \\
\left.\left[{ }_{T \mathrm{TP}} \mathrm{t}_{\mathrm{i}}\left[\mathrm{vP} \text { Pakalat } \text { Pat- tuffa: } \hbar \text { at-a } \mathrm{t}_{\mathrm{k}}\right]\right]\right]\end{array}$ & & *! & *! & & & $* *$ \\
\hline 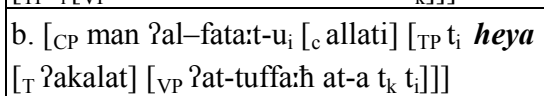 & & & & $* !$ & & $* *$ \\
\hline $\begin{array}{l}\text { c. }\left[\mathrm{CP} \text { man Pal-fata:t- } \mathrm{u}_{\mathrm{i}}[\mathrm{c} \text { allati] }\right. \\
{\left[\mathrm{TTP}_{\mathrm{i}}\left[\mathrm{t}_{\mathrm{T}} \text { ?akalat] [vP } \text { at- tuffa: } \mathrm{h} \text { at-a } \mathrm{t}_{\mathrm{k}} \mathrm{t}_{\mathrm{i}}\right]\right]}\end{array}$ & & & & & $*$ & ** \\
\hline
\end{tabular}

$$
\text { OP SPEC, FAITH [COMP], OB HD, *RES >> Wh-C, STAY }
$$

Tableau 6.

The first candidate loses because of the violation of two top-ranked constraints FAITH [COMP] and OB HD. Like Hebrew, SA alternates resumptive pronouns and gaps (traces) in direct object position, as shown in (28) (Sharvit 1999). However, both languages impose restriction on resumptive pronouns in the highest subject poison (Shlonsky 1992). The interaction between *RES and STAY shows that resumptive derivation exemplified in (b) violates *RES while the gap in (c) emerges as the optimal. For this reason, the interaction between *RES and STAY ends up in favor of *RES. Salzmann (2008) provides evidence in support of this conclusion. Resumptive pronouns derivation, as a matter of fact, is subject to the structural economy notion. That is, resumptive pronouns can be full, weak, clitic or zero.

Resumptive pronouns that function as the object of the preposition are mandatory in SA. Therefore, the deletion of the resumptive pronoun in this case incurs a violation of *Obl/Gap.

*Obl/GAP

No oblique extraction with a gap.

(Kaplan, 2002) 
Tableau 7 compares the possible presence or absence of the resumptive pronoun in the prepositional object position. Constraint interactions below illustrate that the violation of ${ }^{*} \mathrm{Obl} / \mathrm{GAP}$ is suffice to rule a candidate out when the resumptive pronoun is the object of a preposition.

(34) Input: 2al-dža:mifat-u llati darasat fi-ha: l-fata:t-u ma the university that studied-3.sg.f. at which the girl-nom. which 'At which university did the girl study?'

\section{OP SPEC, FAITH [COMP], OB HD, *Obl/ GAP >> *RES, Wh-C, STAY}

\begin{tabular}{|c|c|c|c|c|c|c|c|}
\hline $\begin{array}{l}\text { darasat (x), X=?al-fata:t-u, } \\
\text { (Non-Argument/ Adverb Y=fi l-dža:miat-i). }\end{array}$ & $\begin{array}{c:}\text { OP } \\
\text { SPEC }\end{array}$ & $\begin{array}{l}\text { FAITH } \\
{[\mathrm{COMP}]}\end{array}$ & $\begin{array}{l}\mathrm{OB} \\
\mathrm{HD}\end{array}$ & $\begin{array}{l}* \mathrm{Obl} / \\
\mathrm{GAP}\end{array}$ & *RES & Wh-C & $\begin{array}{l}\text { STAY } \\
\text { STAY }\end{array}$ \\
\hline $\begin{array}{l}\text { a. [CP ma l-dža:miSat-u } u_{i} \text { llati [TP } t_{i} \\
{\left[{ }_{T} \text { darasat }_{k}\left[{ }_{\mathrm{VP}} \mathrm{t}_{\mathrm{i}} \mathrm{t}_{\mathrm{k}} \text { fi Pal-fata:t-u]]] }\right.\right.}\end{array}$ & & & & $* !$ & & $i$ & \\
\hline $\begin{array}{l}\text { b. [CP ma l-dža:miYat- } u_{\mathrm{i}} \text { [C llati } \\
{\left[{ }_{\mathrm{TP}} \mathrm{t}_{\mathrm{i}}\left[\mathrm{vP}_{\mathrm{i}} \text { darasat fi-ha: l-fata:t-u]]] }\right.\right.}\end{array}$ & & & $* !$ & & $*$ & 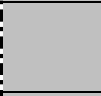 & 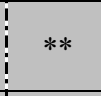 \\
\hline 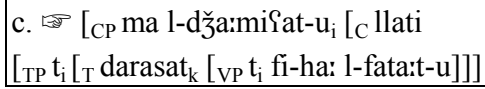 & & & & & $*$ & $*$ & ** \\
\hline
\end{tabular}

Tableau 7.

By deleting the resumptive pronoun, candidate (a) manages to satisfy *RES but to no purpose, since it incurs a violation of the fatal * Obl/GAP. Though it avoids the pitfall of the first candidate, candidate (b) is ruled out as it violates FAITH [COMP], which bans the deletion of the relative pronoun when the relative clause head is present. The last candidate, on the other hand, has no fewer violations of the three rightmost constraints than (a) and (b), but is nevertheless optimal since it has successfully escaped the penalty of all the top-ranked constraints.

The optional phonological manifestation of the relative pronoun and the resumptive pronoun in object position in SA pushes to the fore the optionality issue, in general. Müller (1999) argues that "a candidate can be optimal without having a better constraint profile than all other competitors; it suffices if there is no competitor that has a better constraint profile". In this sense, two candidates may end up as winners for one competition. Evidence in support of this argument stems from Grimshaw's (1997) analysis of English complementizer drop. The question that arises here: should winners of the same competition violate the same constraints? While this remains a possibility, it should be made clear that the two winners may violate different constraints if such constraints are of equal ranking level. 
The schematic constraint ranking below illustrates that the violation of FAITH [COMP] is tolerable as long as the relative clause head is not present. As such, the deletion of the complementizer results in no discernible difference in the semantic or syntactic status of the sentence.

\begin{tabular}{llll} 
Input: Pallaði & \multicolumn{1}{c}{ kasar-a } & S-Subba:k-a & man \\
Who/that/which & broke-sg.masc. & the window-acc. & who \\
'Who broke the window?' & &
\end{tabular}

OP SPEC, OB HD >> FAITH [COMP], Wh-C, STAY

\begin{tabular}{|c|c|c|c|c|c|}
\hline kasar-a $(x, y), X=$ man, $Y=? a \int-\int u b b a: k-a$ & $\begin{array}{c}\text { OP } \\
\text { SPEC }\end{array}$ & $\begin{array}{l}\mathrm{OB} \\
\mathrm{HD}\end{array}$ & $\begin{array}{l}\text { FAITH } \\
\text { [COMP] }\end{array}$ & Wh-C & STAY \\
\hline a. [CP $\operatorname{man}_{\mathrm{i}}$ [TP Rallaði [VP $\mathrm{t}_{\mathrm{i}}$ kasar-a $\left.\left.\left.\int-\int u b b a: k-a\right]\right]\right]$ & & $* !$ & & & $*$ \\
\hline 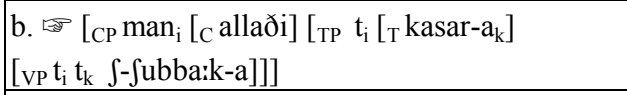 & & & & * & $* * *$ \\
\hline c. $\left[\mathrm{TP}_{\mathrm{TP}} \operatorname{man}_{\mathrm{i}}\left[\mathrm{T}\right.\right.$ kasar-a $\left.\left.\mathrm{a}_{\mathrm{k}}\right]\left[\mathrm{VP} \mathrm{t}_{\mathrm{i}} \mathrm{t}_{\mathrm{k}} \int-\int \mathrm{ubba} \mathrm{k}-\mathrm{a}\right]\right]$ & & & * & & ** \\
\hline
\end{tabular}

Tableau 8 .

Candidate (a) makes a perfect sense from the word order view point, yet it is ruled out since the leftmost projection is left headless. Though candidate (c) is better than candidate (b) in terms of the minimal violation, both candidates are evaluated as optimal for two reasons. First, neither of these candidates incurs a fatal violation of the top-ranked constraints. Second, both forms (b) and (c) do surface and are judged to be grammatical in SA due to the optional presence of the complementizer in both structures. Before proceeding, the optionality of complementizer drop remains valid in direct and indirect questions as long as the relative clause head is not present or when the relative clause head is deleted and a resumptive pronoun is left behind.

\subsection{Indirect wh-questions}

Unlike English, SA does not feature subject-verb inversion either in the matrix or in the subordinate clauses. Therefore, it allows the lexical movement of verbs into the head (X in XP) of both clauses. Figure 6 overleaf, which is a representation of (36), shows this.

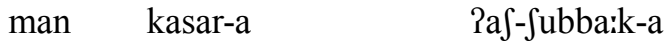

$$
\begin{aligned}
& \text { who broke-3.sg.masc. the window-acc. }
\end{aligned}
$$

'Who broke the window?' 


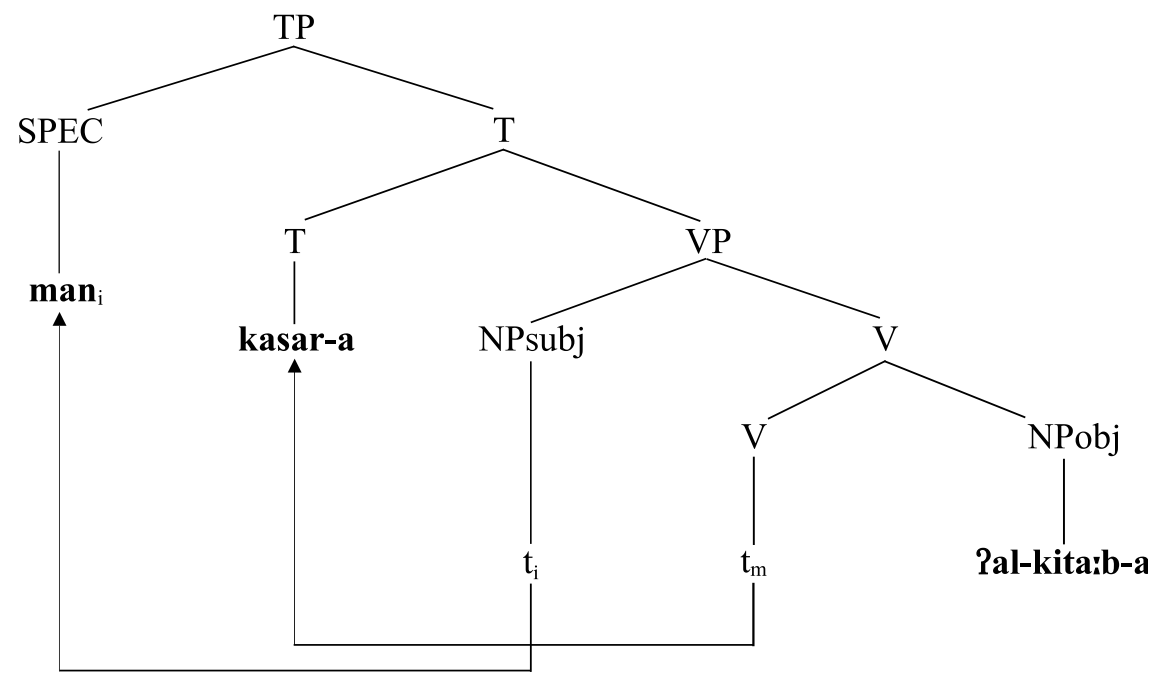

Figure 6. Lexical movement of verb into the head.

Figure 6 shows that the wh-element moves from NPsubj to occupy SPEC TP while the verb moves to the head of TP. According to this analysis, PURE-EP, which is intolerable in English, is expected to be a low-ranked constraint in this variety.

\section{Purity of Extended Projection (PURE-EP)}

No movement into the head of a subordinate clause.

(Grimshaw 1997)

Under a ranking OP SPEC, OB HD >> PURE-EP, STAY, the indirect wh-question formation is predicted. The wh-element undergoes overt movement to SPEC TP so as to escape the violation of the top-ranked constraint OP SPEC. The movement of the whelement to SPEC TP rather than to SPEC CP obeys OB HD, but at the expense of the low-ranked constraint PURE-EP.

$$
\begin{aligned}
& \text { Input: la ?a'rif-u kasar-a } \quad \int-\int u b b a k-a \quad \text { man } \\
& \text { not know-1.sg.masc broke-3p.sg. the window-acc. who } \\
& \text { 'I don't know who broke the window.' }
\end{aligned}
$$

Irrespective of the type of the clause (matrix or subordinate), the OP SPEC must be satisfied in all SA information questions. As such, leaving the wh-word in-situ in (a) results in an immediate elimination of this candidate. The second candidate, on the other hand, wins the race by obeying both OP SPEC (via moving the wh-word to a legitimate specifier), and $\mathrm{OB} \mathrm{HD}$ (via avoiding headless projections). However, the satisfaction of 
OP SPEC, OB HD >> PURE-EP, STAY

\begin{tabular}{|c|c|c|c|c|}
\hline kasara $(x, y), X=$ man, $Y=2 a \int-\int u b b a k a$ & $\begin{array}{l}\text { OP } \\
\text { SPEC }\end{array}$ & OB HD & $\begin{array}{l}\text { PURE- } \\
\text { EP }\end{array}$ & STAY \\
\hline 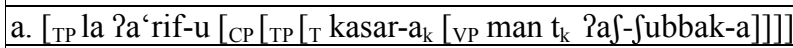 & $* !$ & & * & * \\
\hline 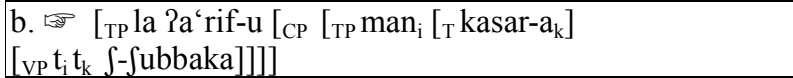 & & 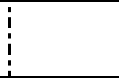 & $*$ & ** \\
\hline 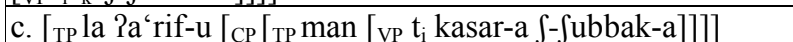 & & $* !$ & & * \\
\hline
\end{tabular}

Tableau 9.

PURE-EP and OP SPEC does not prevent the elimination of candidate (c), as it leaves the TP headless.

The examples in Tableau 10 illustrate that the phonological manifestation of the relative pronoun in indirect questions is a must as long as the relative clause head is present. Therefore, FAITH [COMP] filters out any candidate that violates this constraint.

(39) Input: Rana Pa'rif-u 1-fata:t-a llati $d^{\top}$ araba-ha 1-mudeer-u man I-nom. know- the girl-acc. who/ hit-3.sg.-her that who 1.sg.masc. that headmasternom.

'I know the girl whom the headmaster hit.'

OP SPEC, FAITH [COMP], OB HD >> *RES, Wh-C, STAY

\begin{tabular}{|c|c|c|c|c|c|c|c|}
\hline $\begin{array}{l}\text { daraba }(\mathrm{x}, \mathrm{y}), \mathrm{X}=\text { ?almudeer-u, } \\
\mathrm{Y}=\text { man Palfatat-a }\end{array}$ & $\begin{array}{c}\text { OP } \\
\text { SPEC }\end{array}$ & $\begin{array}{c}\text { FAITH } \\
{[\mathrm{COMP}]}\end{array}$ & $\begin{array}{ll}\mathrm{OB} \\
\mathrm{HD}\end{array}$ & *RES & & & STAY \\
\hline $\begin{array}{l}\text { a. [TP Pana Pa'rif-u [CP man Pal-fatat- } \mathrm{a}_{\mathrm{i}} \\
\left.\left.\left[\mathrm{TTP}_{\mathrm{TP}} \mathrm{t}_{\mathrm{k}} \mathrm{t}_{\mathrm{k}}\left[\mathrm{VP}_{\mathrm{i}} \text { d'arabaha Palmudeer-u } \mathrm{t}_{\mathrm{i}}\right]\right]\right]\right]\end{array}$ & & $* !$ & $* !$ & * & & & $* * *$ \\
\hline 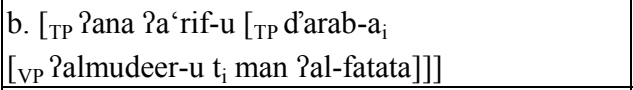 & $* !$ & *! & 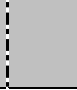 & 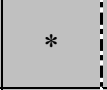 & 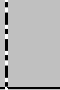 & & * \\
\hline 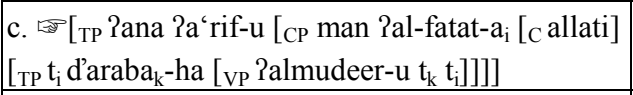 & & & 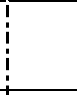 & & 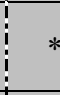 & & $* * *$ \\
\hline 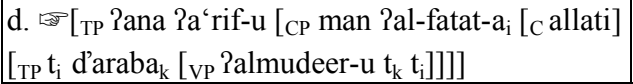 & & & & & & & $* * *$ \\
\hline
\end{tabular}

Tableau 10.

The evaluation in Tableau (10) shows that the satisfaction of the two leftmost constrains OP SPEC and FAITH [COMP] requires the violations of STAY and Wh-C, respectively. 
The deletion of the relative pronoun results in a violation of FAITH [COMP]. This, therefore, explains the elimination of candidate (a). From a general standpoint, candidate (b) is not better than (a) since it incurs two fatal violations. Candidates (c) and (d), on the other hand, come out as optimals by sacrificing the rightmost ranked constraints Wh-C and STAY at the altar of OP SPEC, FAITH [COMP] and OB HD. Before ending this section up, it should be made clear that both forms (c and d), which surface in SA, almost have an equal status in terms of the incurred violations due to the optionality of the presence of the resumptive pronouns in the object position.

\section{Conclusion}

Research on generative grammar has recently witnessed a general shift from the rulebased approach to an output-based model, where all potential linguistic candidates are evaluated with respect to a set of universal markedness and faithfulness constraints. By projecting OT to three types of information questions in SA, this paper has provided a detailed account of the constraints and constraint interactions governing the whmovement. Drawing on the examples providing the database for this paper, it is evident that wh-words/phrases, which originate in argument and non-argument positions, must be in a specifier position in both matrix and subordinate clauses. Furthermore, SA, which imposes some restrictions on prepositional stranding, resumptive pronouns and the complementizer, strictly adheres to OB HD.

\section{REFERENCES}

Alexiadous, A. and E. Anagnosopoulou 1998. "Parametrizing AGR: Word order, V-movement and EPP-checking". Natural Language and Linguistic Theory 16(3). 491-539.

Al-Shorafat, M. 1998. "The Minimalist Program and the structure of Arabic clauses in an Agrbased model". Papers and Studies in Contrastive Linguistics 34. 123-139.

Archangeli, D. 1997. "Optimality Theory: An introduction to linguistics in the 1990s". In: Anchangeli, D. and D.T. Langendoen (eds.), Optimality Theory: An overview. Oxford: Blackwell. 1-32.

Bakir, M. 1980. Aspects of clause structure in Arabic. (Unpublished PhD dissertation, Indiana University, Bloomington.)

Baptista, M. 1995. "On the nature of pro-drop in Capeverdean Creole". Harvard Working Papers in Linguistics 5. 3-17.

Belnap, R.K. and N. Haeri. 1997. Structuralist studies in Arabic linguistics: Charles A. Ferguson's papers, 1954-1994. Leiden: Brill.

Benmamoun, E. 2000. The feature structure of functional categories: A comparative study of Arabic dialects. Oxford: Oxford University Press.

Bolotin, N. 1995. "SA and parametric VSO agreement". In: Eid, M. (ed.), Perspectives on Arabic linguistics VII. Amsterdam: Benjamins. 7-27. 
Broadwell, G.A. 2002. "Constraint symmetry in Optimality Theoretic syntax". In: Butt, M. and T.H. King (eds.), Proceedings of the LFG 02 Conference. National Technical University of Athens.

Carnie, A. 2006. Syntax: A generative introduction. (2nd ed.) Oxford: Blackwell.

Chomsky, N. 1977. "On wh-movement". In: Culicover, P. T. Wasow and A. Akmajian (eds.), Formal syntax. New York: Academic Press. 71-132.

Chomsky, N. 1992. "A minimalist program for linguistic theory". MIT Occasional Papers in Linguistics 1.

Chomsky, N. 1995. The minimalist program. Cambridge, MA: MIT Press.

Chomsky, N. 2000. "Minimalist inquiries: The framework". In Martin, R., D. Michaels and J. Uriagereka (eds.), Step by step: Essays on minimalist syntax in honor of Howard Lasnik. Cambridge, MA: MIT Press. 89-155.

Emonds, J. 1976. A transformational approach to English syntax. Root, structure-preserving and local transformations. New York: Academic Press.

Fakih, A.-H. 2006. "Licensing, movement and feature checking in Standard Arabic: A minimalist approach". Journal of King Saud University 19(2). 37-54.

Farghal, M.A. 1986. The syntax of wh-questions and related matters in Arabic. (Unpublished $\mathrm{PhD}$ dissertation, Indiana University.)

Fassi-Fehri, A. 1993. Issues in the structure of Arabic clauses and words. Dordrecht: Kluwer.

Gouskova, M. 2001. "Split scrambling: Barriers as violable constraints". In: Megerdoomian, K. and L.A. Bar-el (eds.), WCCFL 20 Proceedings. Someville, MA: Cascadilla Press. 220-233.

Greenberg, J. 1966. "Some universals of grammar with particular reference to the order of meaningful elements". In: Greenberg, J. (ed), Universals of language. Cambridge, MA: MIT Press. 73-113.

Grimshaw, J. 1997. "Projection, heads and optimality". Linguistic Inquiry 28. 373-422.

Gutiérrez-Bravo, R. 2002. Structural markedness and syntactic structure: A study of word order and the left periphery in Mexican Spanish. (Unpublished PhD dissertation, University of Santa Cruz.)

Hamdallah, R. and H. Tushyeh. 1998. "A contrastive analysis of English and Arabic in relativization. Papers and Studies in Contrastive Linguistics 34. 141-152.

Kaplan, A. 2002. Patterns of relativization and recent formulations of markedness. (Unpublished $\mathrm{PhD}$ dissertation, University of North Carolina at Chapel Hill.)

Karger, R. 1999. Optimality Theory. Cambridge: Cambridge University Press.

Keer, E. 1999. Som and Optimality Theory. (Unpublished manuscript, University of Massachusetts, Amherst. Available from Rutgers Optimality Archive, 313-0499.) $<\mathrm{http}: / /$ roa.rutgers.edu/>

Lassadi, B. 2005. The syntax and semantics of optional wh-movement: The case of Egyptian Arabic. (Unpublished $\mathrm{PhD}$ dissertation, University of Ottawa.)

Legendre, G. 2001. “An introduction to Optimality Theory in syntax”. In: Legendre, G, J. Grimshaw and S. Vikner (eds.), Optimality-theoretic syntax. Cambridge, MA: MIT Press. 1-27.

Mahfoudhi, A. 2002. "Agreement lost, agreement regained: A minimalist account of word order and agreement variation in Arabic". California Linguistic Notes 27 (2). 1-28.

Marshad, H.A. and S.M. Suleiman 1991. "A comparative study of Swahili ni and Arabic kana as copulative elements". Language Sciences 13(1). 21-37.

McCloskey, J. 1990. "Resumptive pronouns: A-binding and levels of representation in Irish". In: Hendrick, R. (ed.), Syntax of the modern Celtic languages (Syntax and Semantics 23). New York: Academic Press. 199-248.

Mohammad, M.A. 2000. Word order, agreement and pronominalization in Standard and Palestinian Arabic. Philadelphia: Benjamins. 
Müller, G. 1999. "Optionality in Optimality-Theoretic syntax”. GLOT International 4(5). 3-8. Nouhi, Y. 1996. Wh-constructions in Moroccan Arabic. (Unpublished MA thesis, University of Ottawa.)

Ouhalla, J. 1994. "Verb movement and word order in Arabic". In: Lightfoot, D. and N. Hornstein (eds.), Verb movement. Cambridge: Cambridge University Press. 41-72.

Pesetsky, D. 1997. "Optimality theory and syntax: Movement and pronunciation". In: Archangeli, D. and D.T. Langendoen (eds.), Optimality theory: An overview. Blackwell. 134170.

Prince, A. and P. Smolensky. 1993. Optimality theory: Constraint interaction in generative grammar. (Ms., Rutgers University, New Brunswick, NJ, and University of Colorado, Boulder.)

Salzmann, M. 2008. "Variation in resumption requires violable constraints. A case study in Alemannic relativization. In: Broekhuis, H. and R. Vogel (eds.), Optimality Theory and minimalism: Interface theories. Potsdam: Potsdam University. 99-132.

Sharvit, Y. 1999. "Resumptive pronouns in relative clauses". Natural Language and Linguistic Theory 17. 587-612.

Shlonsky, U. 1992. "Resumptive pronouns as a last resort". Linguistic Inquiry 23(3). 443-468.

Shlonsky U. 1997. Clause structure and word order in Hebrew and Arabic: An essay in comparative Semitic syntax. Oxford: Oxford University Press.

Shlonsky, U. 2002. "Constituent questions in Palestinian Arabic". In: Ouhalla, J. and U. Shlonsky (eds.), Themes in Arabic and Hebrew syntax. Dordrecht: Kluwer. 137-160.

Shooshtari, Z.G. 2009. "Generative syntactic transfer in L2 and L3 acquisition via the channel of translation”. English Language Teaching 2(1). 129-149.

Tamari, E. 2001. Sentential negation in English and Arabic: A minimalist approach. (Unpublished $\mathrm{PhD}$ dissertation, University of Kansas.)

Wahba, W.A. 1984. Wh-constructions in Egyptian Arabic. (Unpublished PhD dissertation, University of Illinois at Urbana-Champaign.)

Zughoul, M.R. 1980. "Diglossia in Arabic: Investigating solutions". Anthropological Linguistics 22(5). 201-217.

\author{
Address correspondence to: \\ Mousa A. Btoosh \\ Dept. of English Language and Literature \\ Al-Hussein Bin Talal University \\ P.O. Box 20 \\ Ma'an \\ Jordan \\ mbtoosh@ahu.edu.jo
}

